\title{
Letters
}

\section{Histopathological findings in a cystectomy specimen after six} years of catheterisation

It is well known that urinary incontinence, chronic urinary infections and retention are common urological complications in patients with a neuropathic bladder due to multiple sclerosis $(1,2)$. In the treatment of these patients long time catheterisation is often indicated and the resulting histopathological changes of the bladder are well known.

We report on a 51-year-old female patient with multiple sclerosis for over ten years. She had total incontinence and had an indwelling catheter for six years. Surgeons performed a cystectomy and an intestinal ureterostomy (method after Bricker).

In the pathological examination we observed a cystectomy specimen which measured $9 \times 7 \times 6 \mathrm{~cm}$. The bladder wall was nonelastic, stiff and was $3,5 \mathrm{~cm}$ in thickness. The mucosa was irregular, thickened and greywhite in colour.

Microscopically the bladder showed severe fibrosis in the lamina propria and muscularis (Figure 1). Some fibrotic areas were hyalinized (Figure 2). Furthermore we found a dense inflammatory infiltration which consisted of mononuclear cells in each layer of the bladder wall (Figure 3). The muscularis showed a dissociation of smooth muscle cells caused by the increased fibrosis and a leiomyomatous-like hyperplasia (Figure 4). The transitional epithelium showed multifocal squamous metaplasia. An immunohistochemical study for S-100 protein, an antigen expressed by neural structures, revealed a marked hypertrophy and hyperplasia of the nerve fibers localized in the lamina propria and the muscularis.

This case demonstrates the effects of chronic indwelling catheters after six years of catheterisation. The results reveal the necessity for constant clinical surveillance in

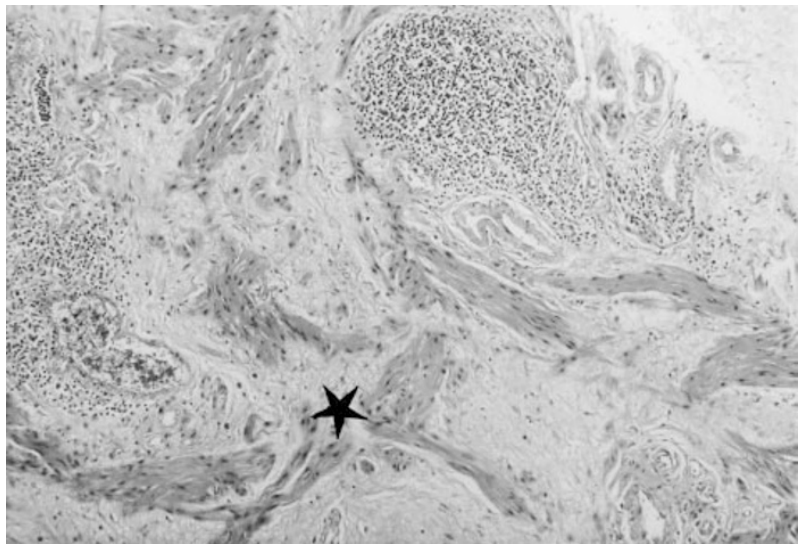

Figure 1 Severe transformation of the bladder wall with increased fibrosis, circumscribed inflammatory infiltrate and separated bundles of smooth muscle cells (star). $(\mathrm{HE} \times 60)$

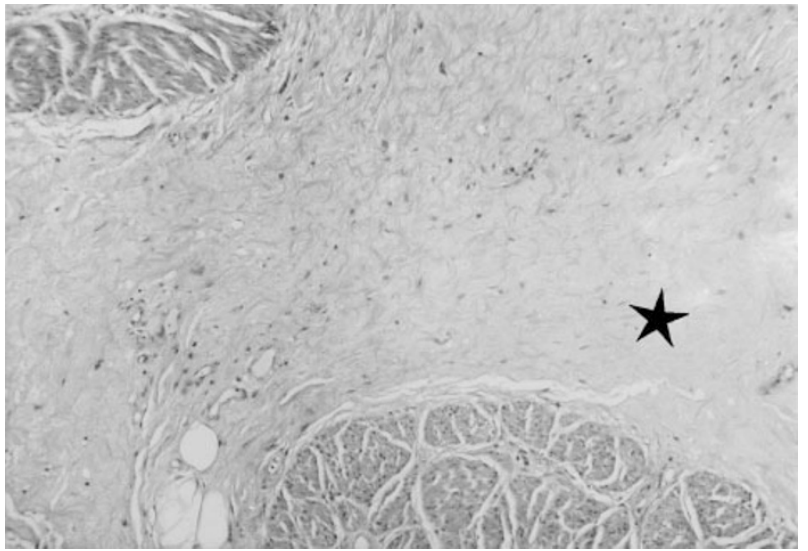

Figure 2 Fibrosis of the bladder wall with hyalinized areas (star) $(\mathrm{HE} \times 100)$

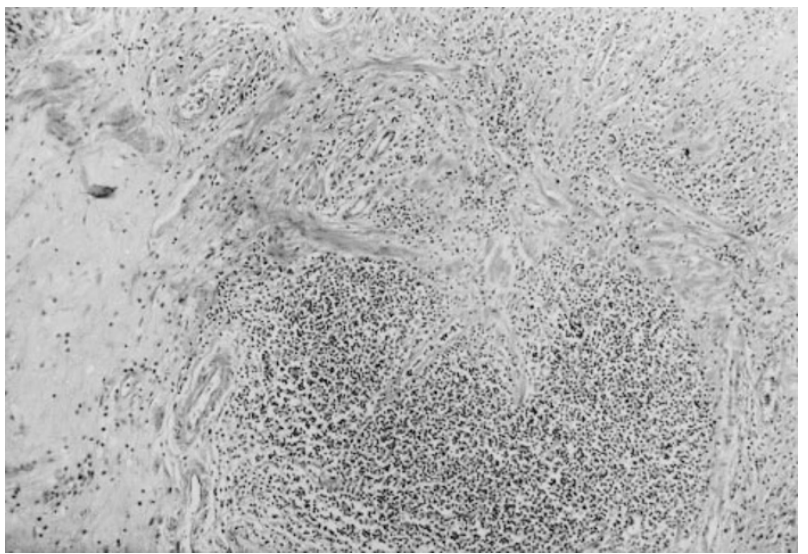

Figure 3 The dense inflammatory infiltrate consists of mononuclear cells. $(\mathrm{HE} \times 60)$

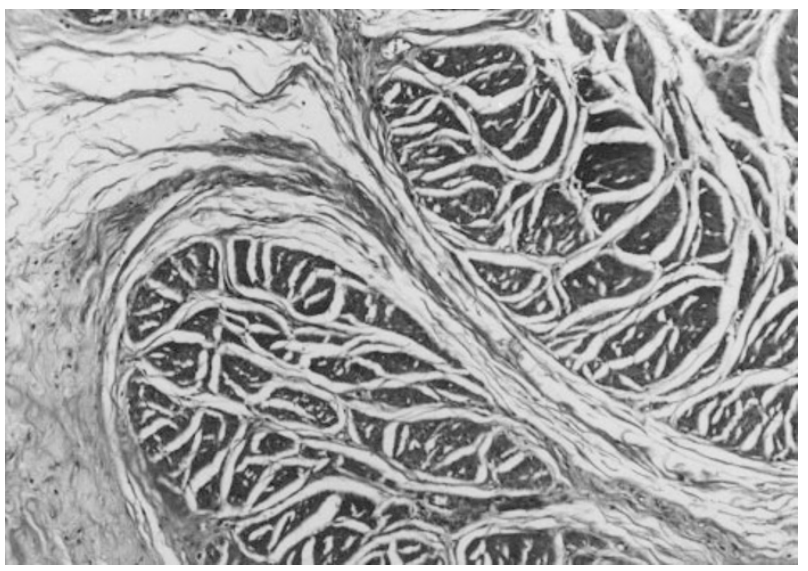

Figure 4 Dissociation of smooth muscle cells caused by increased fibrosis $(\mathrm{HE} \times 140)$ 
such patients, with the aim of avoiding the necessity for such radical surgical interventions.

J Janzen, MD and PN Vuong, MD, PhD Unité d'anatomie et de cytologie pathologiques Hôpital St. Michel 33, rue Olivier de Serres F-75730 Paris

D Gonties, MD Clinique de Tournan 2, rue Jules Lefebvre F-77220 Tournan-en-Brie

France

\section{References}

1 Amarenco G, Bosc S, Boiteau F.Les complications urologique de la sclérose en plaques, 180 cas. Presse med, 1996; 25: 1007 - 1010 .

2 Bradley WE. Urinary bladder dysfunction in multiple sclerosis. Neurology 1978; 28: 52-58.

Neurological deficit in a consecutive series of vertebral fracture patients with bony fragments within the spinal canal Rosenberg et al. Spinal Cord (1997) 35: 92-95

The authors made a statement that 'The neurological outcome of patients with post-traumatic bony encroachment of the spinal canal is not well documented in the literature etc'. Unfortunately, it does not appear that they have made an adequate search of the literature on the subject.

I would like to draw the attention of readers to Spinal Cord to the following two important publications which are both in the Index Medicus: 'Reflections on the neurological significance of bony canal encroachment following traumatic injury of the spine in patients with Frankel C, D and E presentation' by WS El-Masry, S Katoh, A Khan from the Midlands Centre for Spinal Injuries, Robert Jones \& Agnes Hunt Orthopaedic and District Hospital, Journal of Neurotrauma 1993 Volume
10. The title of the other publication is 'Neurological injury in thoraco-lumbar burst fractures' by D Limb, DL Shaw and RA Dickson, St James University Hospital, Leeds, England, Journal of Bone and Joint Surgery, Volume 77B No. 5 September 1995.

WS El-Masry

Consultant in Spinal Injuries Medical Director

Midlands Centre for Spinal Injuries Owestry, Shropshire, England

\section{Reply from Dr N Rosenberg and Professor H Stein}

Thank you for your remarks on our article. When we emphasised the inadequate documentation of the neurological outcome in patients with spinal canal narrowing we cited the most quoted publications in the years 1956-1993 (references $3-11)$. Although we were aware of other publications on this subject (with the similar observations), our intention was not to write a review of the relevant literature but rather to present our findings. We think that although several authors have made similar observations, the dilemma of the 'appropriate' approach to the patients with post traumatic spinal canal narrowing is far from being completely solved. For this reason we intended to add our data and conclusions to existing observations. Unfortunately we think that the existing knowledge, including your and our works, is not yet sufficient but the contributions may bear weight.

Regarding your remark that the question of the poor correlation between spinal canal encroachment and the neurological outcome was first discussed in 1992, this subject has been discussed earlier by several authors and some of the most important reports are in the list of references provided in our article $(12-20)$. We are also confident that if you perform a further search in various medical databases you will find these and even more early reports with similar conclusions.

Dr Nahum Rosenberg and Porfessor Haim Stein Department of Orthopaedic Surgery 'A' Rambam Medical Center Haifa, Israel 